\title{
Biological effects of radiation on cancer cells
}

\author{
Jin-song Wang, Hai-juan Wang ${ }^{*}$ and Hai-li Qian ${ }^{*}$
}

\begin{abstract}
With the development of radiotherapeutic oncology, computer technology and medical imaging technology, radiation therapy has made great progress. Research on the impact and the specific mechanism of radiation on tumors has become a central topic in cancer therapy. According to the traditional view, radiation can directly affect the structure of the DNA double helix, which in turn activates DNA damage sensors to induce apoptosis, necrosis, and aging or affects normal mitosis events and ultimately rewires various biological characteristics of neoplasm cells. In addition, irradiation damages subcellular structures, such as the cytoplasmic membrane, endoplasmic reticulum, ribosome, mitochondria, and lysosome of cancer cells to regulate various biological activities of tumor cells. Recent studies have shown that radiation can also change the tumor cell phenotype, immunogenicity and microenvironment, thereby globally altering the biological behavior of cancer cells. In this review, we focus on the effects of therapeutic radiation on the biological features of tumor cells to provide a theoretical basis for combinational therapy and inaugurate a new era in oncology.
\end{abstract}

Keywords: Radiation, Cancer cells, Biological features, Combinational therapy

\section{Background}

Tumor radiotherapy is a technique that is used to inhibit and control growth, metastasis and proliferation of malignant tumor cells using various types of ionizing radiation. Over the past few decades, the development of molecular biology and experimental techniques has further elucidated the effects of radiation on the biological properties of cancer cells. During tumor treatment, radiation is considered to be a "double-edged sword" because it not only affects the proliferation, metastasis and other biological processes of neoplasms, but may also genetically modify normal tissues, causing damage to non-tumor cells, which is a detrimental effect on the body that we do not expect. Traditionally, it has been revealed that irradiation can directly affect malignant cells by affecting DNA structure stability and repair processes, triggering DNA double-strand breaks (DSBs) and inducing therapeutic effects against tumor cells, such as apoptosis, necrosis, senescence, and abnormal mitosis $[1,2]$.

\footnotetext{
*Correspondence: hlj-whj@163.com; qianhaili001@163.com

State Key Laboratory of Molecular Oncology, National Cancer Center/

National Clinical Research Center for Cancer/Cancer Hospital, Chinese

Academy of Medical Sciences and Peking Union Medical College, RM6102,

New Research Building, 17 Panjiayuan Nanli, Chaoyang District 100021,

Beijing, China
}

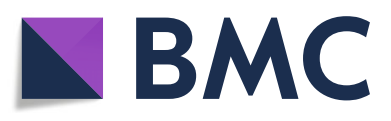

(๑) The Author(s). 2018 Open Access This article is distributed under the terms of the Creative Commons Attribution 4.0 International License (http://creativecommons.org/licenses/by/4.0/), which permits unrestricted use, distribution, and

reproduction in any medium, provided you give appropriate credit to the original author(s) and the source, provide a link to the Creative Commons license, and indicate if changes were made. The Creative Commons Public Domain Dedication waiver (http://creativecommons.org/publicdomain/zero/1.0/) applies to the data made available in this article, unless otherwise stated. disturbs the structure of neoplasm cells, such as the cell membrane and organelles but also interferes with cell signal transduction and regulation, changing neoplasm cells immunogenicity and their microenvironment $[3,4]$. Additionally, irradiated cancer cells can deliver a bystander response signal to adjacent non-irradiated tumor cells, which kills adjacent neoplasm cells and protects normal tissue from damage caused by rays [5]. With regard to radiotherapy of malignant tumors, it is necessary to ensure that the correct dose is projected in the correct manner to the precise position of the patient to achieve the best possible therapeutic effect while harming normal tissue as little as possible. Since the introduction of the concept of "precision medicine" in 2011, the emphasis has been placed on individualized and accurate treatment, which are aimed at improving the effectiveness of cancer diagnosis and treatment. A better understanding of the response of malignant tumors to radiation at the molecular, cellular and tissue levels will be advantageous to form new strategies for the combined treatment of tumors. 


\section{Radiation causes DNA damage}

Apoptosis, necrosis, and senescence of cancer cells induced by DNA damage are the major effects of radiation on tumor tissue and are beneficial effects of radiation for cancer therapy. Radiation directly causes DNA damage like single-strand breaks (SSBs), DSBs, DNA crosslink and DNA-Protein crosslinks or induces damage indirectly to DNA by reactive oxygen species (ROS)/reactive nitrogen species (RNS). Of these, DSBs, an initiating factor of chromosomal rearrangements that increase in a linear-quadratic function under high dose rates (HDR) of radiation, are considered to be the most harmful lesion induced by radiation [6-9]. Quick phosphorylation of histone $\mathrm{H} 2 \mathrm{AX}$ on serine $139(\gamma \mathrm{H} 2 \mathrm{AX})$ is deemed to be a sensitive marker of ionizing radiation-induced DSBs [10]. Collis et al. [11] observed that decreased activation of $\gamma \mathrm{H} 2 \mathrm{AX}$ following low-dose-rate exposures compared with high-dose-rate radiation in cancerous and normal human cells indicating that DNA damage induced by low-dose-rate radiation might be able to be repaired efficiently. The responses of tumor cells to heavy radiation-induced DNA damage are transmitted from DNA damage sensors and cell cycle regulators and can be categorized into three stages: DNA damage induction, DNA damage signal pathway activation and the repair phase of DNA damage [2, 12].

Similar to DSBs, within a certain range, the yield and complexity of SSB and non-DSB cluster damage are positively correlated with the radiation dosage. However, DSBs are relatively unmanageable. DSBs are restored by two main pathways, homologous recombination and non-homologous end joining (NHEJ) $[13,14]$. If DNA damage is renovated effectively and precisely, cells recover their normal functions; otherwise, chronic DNA damage will trigger apoptosis or cell senescence [15]. Moreover, radiation can activate protein tyrosine phosphatase non-receptor type 14 (Ptpn14) through DNA damage signaling in a mouse embryonic fibroblasts model expressing H-Ras ${ }^{\mathrm{v} 12}$ [16]. Activated Ptpn14 can inhibit the proliferation of pancreatic cancer cells by negative regulation of the YAP oncogene [16]. Furthermore, Jutta's group demonstrated that HeLa cells exposed to 10Gy of $\mathrm{X}$-irradiation harbored the characteristics of mitotic catastrophe and increased intra-nuclear chromosome territories compared with a control group, and thus initiating cell apoptosis [17]. However, there are still some cancer cells that can induce endopolyploidization as an escape route from cell death, which emphasizes the significance of precisely distinguishing tumor cells and their variants.

\section{Rays affect the performance of cancer cell organelles Radiation damages the endoplasmic reticulum}

Radiation-induced damage to organelles may also play an important role regarding the effects of radiation. Studies have shown that IR-induced tumor cell death is associated with endoplasmic reticulum (ER) disturbances [18]. As a major target organelle of radiation, ER is highly sensitive to changes in the internal environment. Milieu interne changes induced by radiation will cause an endoplasmic reticulum stress (ERS) response, which leaves tumor cells in a stress state. A mild ERS-activated unfolded protein response (UPR), endoplasmic reticulum overload reaction (EOR) or sterol regulatory element binding protein (SREBP) can not only initiate autophagy and remove misfolded proteins to restore ER homeostasis and promote cell survival but also stimulate the expression of protective molecules, such as endoplasmic reticulum chaperones, to protect cells from damage [19]. However, when the radiation dose is large enough, sustained and excessive ERS will have a variety of biological effects on tumor cells. The endoplasmic reticulum may cause autophagic cell death by over-activating the autophagy pathway; additionally, the ER may initiate specific apoptotic pathway to promote tumor cell apoptosis [20].

\section{IR-induced ribosomal changes}

Ribosomes, a type of intracellular ribonucleoprotein particle, are mainly composed of RNA (rRNA) and proteins. Their indispensable function is to translate amino acids into polypeptide chains according to the mRNA sequence, which lays foundation for maintaining the systematical operation of bioactivities and given their multifunctional and regulatory activities, numerous studies have illustrated that ribosomes play important roles in the initiation and development of cancer [21-23]. HyeSook's group indicated that 4Gy of IR dissociated the MIF-rpS3 complex (migration inhibitory factor, MIF and ribosomal protein S3, rpS3) by inducing casein kinase $2 \alpha(\mathrm{CK} 2 \alpha)$-mediated rpS3 phosphorylation and that separation of MIF-rpS3 affected the NF-kB pathway, concomitantly stimulated cancer-associated inflammation and promoted metastasis of NSCLC cells [24]. Similarly, Yang et al. [25] demonstrated that $\mathrm{CK} 2 \alpha$ - and PKC-induced phosphorylation of rpS3 and TNFR-associated factor 2 (TRAF2) granted NSCLC cells radioresistance by activating the NF- $\mathrm{kB}$ signaling pathway; however, CK2 $\alpha$ - and PKC-deficient NSCLC cells are radio-responsive. Of note, an attempt to regulate $\mathrm{rpS} 3$ and MIF or TRAF2 in combination with radiation may have a high pharmacological therapeutic potency by retaining the normal activity of rpS3. Clinically, by analyzing the serum composition changes of 35 patients with prostate cancer before and after treatment, Ingrosso et al. [26] indicated that the ribosomal P0 protein appeared to be increased according to the degree of exposure along with a high immunogenic antigen, and consequently, its immunogenicity increased following RT, which highlights that the generation of anti-P0 autoantibodies after IR could have clinical significance. 


\section{Radiation affects the behavior of mitochondria}

In addition to endoplasmic reticulum disorders, radiation exposure has a significant effect on the biological behavior of the mitochondria in tumor cells. Kam et al. [27] found that radiation can directly promote the release of cytochrome $\mathrm{C}(\mathrm{Cyt}-\mathrm{c})$ by releasing ROS or by indirectly triggering Cyt-c-induced apoptosis through altering the permeability of the mitochondrial membrane both in vitro and in vivo. Cyt-c, released from the mitochondria into the cytoplasm, forms a complex with the apoptotic factor Apaf-1. Caspases-9, recruited by the CARD domain of the Cyt-c/ Apaf-1 complex, can be activated by homo-activation, which is a motivation to initiate apoptotic signaling pathways mediated by caspases-3 and caspases-7. As shown by Walsh et al. [28] via in situ live cell imaging of individual mitochondria stained with Tetramethylrhodamine ethyl ester, targeted irradiation triggers mitochondrial membrane depolarization, which can induce cytochrome c release and is involved in apoptosis. Simultaneously, Fachal et al. [29] incubated a cytoplasmic extract of irradiated cells with normal cells and found that the extract induced DNA fragmentation of the normal nucleus, illustrating that the cytoplasm might also be an important target of the radiotoxic effect. Moreover, the direct action of radiation on mitochondrial DNA (mtDNA) could activate programed cell death by itself [29]. In summary, the impact of radiation on the biological properties of tumor cell organelles also has a significant impact on the development and recurrence of cancer [30].

\section{Irradiation-induced lysosomal damage}

Lysosomes are important organelles of animal cells that digest various biological macromolecules in the body and involved in cellular metabolism, immunity and hormone secretion regulation and other activities. If the lysosomal membrane is damaged by environmental stress including radiation, various hydrolases in the lysosome enter the cytoplasm and disintegrate the cell. Furthermore, Lennart assessed radiation-induced lysosomal destabilization of the lymphoma J774 cell line in vitro and found that a 40Gy radiation dose triggered remarkable upregulation of intra-lysosomal labile iron, which resulted from "reparative auto-phagocytosis" secondary to radiation-induced lysosomal damage, along with an outflow of lytic enzymes as well as abnormal iron and consequent cellular injuries [31]. When different dosages of X-rays (2Gy, 4Gy and 8Gy, respectively) were given to lung adenocarcinoma A549 cells, the number of lysosomes was significantly increased, as detected by the Lyso-Tracker Red fluorescent probe, and senescence of A549 cells was further aggravated. Radiation can exacerbate the aging of cancer cells in a lysosome-related manner or not. Smooth muscle protein 22-alpha (SM22 $\alpha$ ) activates the p16INK4a/retinoblastoma signaling pathway, promoting HepG2 cell senescence, which is caused by a subclinical dose of $\gamma$-radiation ( 0.05 and $0.1 \mathrm{~Gy}$ ) [32]. Besides, apoptosis in UVA-irradiated keratinocytes is co-mediated by lysosomal exocytosis combined with caspase-8, indicating the essential role that lysosomes play in irradiation-induced effects. Biologically, lysosomes are indispensable sites and regulators of cancer cell autophagy processes, which are the essential inducers of tumor multidrug resistance (MDR), whereas lysosomal dysfunctionality resulting from irradiation could reverse this effect. Despite limited data on lysosome-mediated tumor therapy, the irreplaceable function of lysosome makes it a promising target for oncotherapy.

\section{Radiation affects the plasma membrane}

The use of a micro-beam system to selectively irradiate a nuclear-free sphingo-like ceramide membrane confirmed that the plasma membrane is another target of ionizing radiation. On one side, radiation can directly affect the composition of the tumor cell membrane, such as membrane receptors, lipids and membrane proteins, which have significant effects on cell membrane permeability, integrity, and mobility. On the other side, radiation induces amounts of ROS and RNS, which affect a number of intracellular signaling pathways and regulate a variety of cell functions and structures, such as apoptosis, proliferation, cytoskeleton and morphological changes.

\section{Radiation affects the cell membrane biological properties}

Stability of cell membrane is instrumental to the occurrence and development of malignant neoplasms. Radiation can directly cause corrosive damage to the cell membrane or indirectly alter the biological characteristics of the cell membrane by affecting the composition of the cell membrane. When radiation acts on the cell membrane, it causes corrosive damage to the cell membrane diametrically, which affects the permeability, integrity, and mobility of the cell membrane and, eventually leads to cell disaster [33]. In addition, radiation can directly activate sphingomyelinases on the tumor cell membrane, and the destruction of polar components of tumor cells from the degradation of lipids by sphingomyelin enzymes leads to impairment of the membrane barrier, which is critical to the integrity of tumor cells [3]. Rays can also affect the intensity and activity of membrane proteins by disturbing peptide links, hydrogen bonds and disulfide linkages, which are significant for maintaining normal membrane protein structures [34, 35]. Immunologically, environment stress, including radiation, initiates translocation of heat shock protein 70 (Hsp70) from an intracellular bio-site to the extracellular milieu, where it can originate an innate immune response under the condition of pro-inflammatory cytokines or unleash 
adaptive immune system in the presence of tumor-derived peptides via antigen cross-presentation [36-38]. Fractionated radiation $(5 \times 2 \mathrm{~Gy})$ facilitates further Hsp70 release and membrane expression in dying cancer cells and hence augments the immune-recognization of $\mathrm{Hsp} 70^{+}$tumor cells by TKD/IL-2 activated NK cells $[39,40]$, indicating the essential roles of HSPs as targets for adaptive and innate anti-tumor immune responses. The therapeutic efficacy of united therapy mediated by intratumoral dendritic therapy and radiation rose immeasurably by a co-injection with recombinant Hsp70 demonstrated in CT26 colorectal cancer mouse models [41]. Given the importance of cell membranes to tumor cells and irradiation-induced enhanced immunotoxicity via modulating membrane elements expression, radiotherapy-combined strategies to target tumor cell membranes may be a promising treatment.

\section{Radiation regulates cell membrane signal transduction}

Another key event of radiation acting on tumor cells is that ionizing radiation regulates plasma membrane-related signaling molecules and secondary messengers of neoplasm cells. Based on in vitro assays, Goldkorn [42] and Lammering [43] et al. reported that radiation can activate epidermal growth factor receptor(EGFR) through a non-ligand-dependent pathway and provoke downstream MAPK and $\mathrm{PI}_{3} \mathrm{~K}$ pathways, which are powerful mediators of malignant growth and proliferation. In a study on the effects of radiotherapy on gliomas, Park found that radiation switched on the EGFR-mediated p38/Akt and $\mathrm{PI}_{3} \mathrm{~K} /$ Akt signaling pathways, which led to increased glioma cell metastasis and invasive ability by up-regulating matrix metalloproteinase 2 (MMP-2) expressions [44]. Alternatively, radiation also promotes cancer cell proliferation, spreading and invasion by upregulating integrin, which is closely related to the diversified biological behaviors of cancer cells [45], or by increasing hypoxia inducible factor (HIF) and activating the hepatocyte growth factor (HGF) /c-Met signal transduction pathway [46]. By contrast, injuries to membrane receptors of tumor cells caused by ionizing radiation can result in a downstream signal transduction pathway imbalance, which causes cellular metabolic pathway confusion and even apoptosis or death. Thus, radiation has dual-functions on cancer cells, not only by damaging DNA to inhibit tumor proliferation but also by changing the expression of molecules associated with invasion and metastasis to promote or restrain tumor development. Accurate descriptions of radiation-sensitive oncology therapeutic signaling pathways will further advance the development of personalized radiotherapy.

\section{Radiation alters the biological behavior of tumor cells}

As normal cells are transformed into cancer cells, they harbor a series of special properties that contribute to the development and progression of the tumor.
According to Weinberg's group, there are ten biological characteristics that are hallmarks of tumors and have led to widespread concern [47]. Based on the relationship between radiation and cancer cells, we integrate the ten properties into six irradiation-related damage scales: 1). The effects of radiation on cell proliferation scale including four of the ten hallmarks (infinite proliferation, escaping growth inhibition, resistance to cell death, and permanent replication); 2). The effects of radiation on invasion and metastasis scale is composed of two of the ten hallmarks (induction of angiogenesis, activation of invasion and metastasis); 3). The effects of radiation on cancer-promoting inflammation scales; the remained three scales involve genomic instability and abnormal energy metabolism what we had discussed above referred to DNA damage and mitochondria, respectively, and immunogenicity which will be discussed later. Therefore, we will kick something around the first three scales. Further elucidating the mechanism of radiation on the iconic biological ability of the tumor will provide a solid theoretical basis for radiotherapy and combined therapy of neoplasm.

\section{Effects of radiation on the proliferation scale}

Unrestricted proliferation is a major barrier to defeat cancer. The Jumonji domain-containing protein $2 \mathrm{~B}$ (JMJD2B) is a histone demethylase that promotes the development and progression of gastric cancer, both in mice and human [48]. Kim et al. [49] found that radiation downregulated the level of JMJD2B, which inhibited the expression of cyclin A1 (CCNA1) and, ultimately restrained the proliferation of human gastric cancer AGS cell lines. Additionally, radiation also has a significantly negative influence on squamous cell carcinoma proliferation. As demonstrated by Geraldo et al. [50], high dose rate (HDR) short-range radiation can induce $G_{2} / M$ phase arrest of the radiation-resistant human squamous cell carcinoma A431 cell line by triggering A431 to enter a mitotic death state, which eventually inhibits tumor cell proliferation. This is consistent with the above discussion that radiation-induced DNA damage will result in activation of cell cycle checkpoints and disruption of cell cycle. However, besides depressing proliferation of tumor cells, radiation can also induce ordinary cancer cells to be transformed into induced cancer stem cells (iCSCs), which not only have a strong resistance to radiation but also promote tumor proliferation. According to Lagadec et al. [51], differentiated normal breast cancer cells can be reprogrammed by rays to obtain stemness and develop into induced breast cancer stem cells (iBCSCs), significantly reducing the therapeutic effect. Therefore, to achieve better anti-tumor efficacy, it is necessary to combine radiotherapy with other treatment measures that can inhibit the 
induction of tumor cells without stemness to tumor stem cells.

\section{Effects of radiation on the invasion and metastasis scale} Growing experiments show that radiation can promote tumor epithelial-mesenchymal transition (EMT), which promotes cancer metastasis. EMT is a phenotypic switch that allows tumor cells to detach from intercellular junctions to facilitate metastasis. Jung et al. [52] found that radiation upregulates TGF- $\beta$ in human lung adenocarcinoma A549 cells, which can induce tumor EMT and enhanced its ability to invade and metastasize. As illustrated by experiments, radiation promotes the invasion and metastasis of colorectal cancer (CRC) cells by enhancing the activity and expression of matrix metalloproteinases (MMPs) [53-55], and studies have elaborated that EMT is related to tumor invasion and metastasis [56-58]. Kawamoto et al. [59] found that radiation promotes a shift of CRCs and also suggested that this radiation-enhanced aggressiveness is associated with morphological and molecular changes, consistent with a shift to a mesenchymal-like phenotype. Confirmed by Zhang et al. [60], when breast cancer MCF-7 cells were exposed to 20Gy rays, expression of the epithelial cell markers CK-18 and E-cadherin was down-regulated, while expression of the stromal cell markers fibronectin and vimentin was up-regulated. The enhancement of invasiveness by radiation in breast cancer MCF 7 cells was confirmed through matrigel invasion experiments, suggesting that radiation promotes breast cancer cell EMT and boosts invasion [60]. In conclusion, the effect of radiation on the phenotype of cancer cells is consistent with EMT conversion, suggesting that combining inhibitors of EMT- activating molecules and radiotherapy may be an effective method to treat cancer.

Induction of angiogenesis is another important force that drives rapid cancer cell metastasis and poor patient prognosis. Tumor angiogenesis is a multifactorial and multi-modal complex process. The changes of vascular endothelial growth factor (VEGF), extracellular matrix-associated protease, adhesion factor and so on contribute to the tumor angiogenesis process. Radiation up-regulates the transcriptional level of VEGF-C in the lung cancer A549 cell line by activating the $\mathrm{PI}_{3} \mathrm{~K}$-Akt-mTOR pathway and increases phosphorylation of 4EBP and eIF4E which as a result promotes tumor neovascularization and endothelial cell proliferation [61]. Consistently, rays promote melanoma angiogenesis by activating TLR4-MYD88-driven inflammatory response [62]. However, radiation inhibits tumor angiogenesis but can easily relapse, which makes joint therapy indispensable. It has been demonstrated by in vitro experiments that radiotherapy plus the autophagy inhibitor 3-methyladenine can more effectively inhibit angiogenesis of the human esophageal squamous cell carcinoma EC9706 cell line compared with radiotherapy alone [63]. In addition, DNA-dependent protein kinase catalytic subunit (DNA-PKcs) inhibitors can eliminate the radiation-induced up-regulation of VEGF and HIF-1 $\alpha$ in glioblastoma [64]. Therefore, the effective combination of radiotherapy and DNA-PKcs inhibitors may be a potential union to address glioblastoma under certain circumstances. Illustrating the working mechanism of radiation on the hallmarks of tumor cells will lead to more effective options for cancer therapy.

\section{Effects of radiation on the cancer-promoting inflammation scale}

Large numbers of immunocytes, cytochemotactic factors, and growth factors that are beneficial to proliferation, invasion, adhesion and angiogenesis promote the initiation and development of cancer in the tumor inflammatory microenvironment (TIM). Tumor resistance to radiation therapy is not only related to the tumor type and tissue distribution but also to the TIM, which has made the relationship between radiation and inflammatory microenvironment a promising topic in recent years [65]. NK cells, immune cells in the TIM, harbor a variety of immunological functions. Early studies manifested that X-ray irradiation enhances the sensitivity of NK cells, which reduces the secretion of exogenous proteins and further retards the growth of malignant tumors [66]. Comparably, T helper cells 17 (Th17) in TIM antagonized Th1 and thus repressed the production of INF- $\gamma$ [67], however proved by Wang's team that LDR-induced activation of ataxia telangiectasia mutated (ATM) markedly decreased IL-23 secretion and consequently disturbed Th17 responses [68]. In addition to immunocytes, there are still some regulatory factors in the TIM. At an advanced stage in the tumor development, TGF- $\beta$ no longer acts as a tumor suppressor, but instead stimulates angiogenesis to some extent, promoting EMT, thereby accelerating tumor development [69]. In summary, precisely distinguishing the composition of the TIM and the diverse responses of the tumors to different doses of radiation are a great help for oncotherapy. It is noteworthy that immune cells or cytokines do not exert a function in the TIM independently but rather in the integrated networks of antineoplastic and oncogenic factors.

\section{Radiation affects the tumor immune response}

Immunotherapy plays an increasingly important role in tumor therapy. Studies of the mechanisms that regulate the immune system and interactions between tumor cells and immune factors have laid a solid theoretical foundation for the treatment of multiple malignant tumors [70]. Moreover, recent studies have shown that tumor radiotherapy is closely interrelated with immune effects, and quantities of experiments have illustrated that radiation affects the division or metastatic biological 
processes of tumor cells indirectly by impacting the tumor microenvironment and immunogenicity [71, 72]. Parker et al. [73] and Magné et al. [74] found that when a single high dose of radiation was applied to tumor tissue, it regulated the expression of many apoptotic and anti-apoptotic genes by activating the NF- $\kappa B$ signaling pathway and inducing the occurrence and maintenance of immune $T$ cells, $B$ cells and antigen presenting cells (APC). It has been shown that local tumor radiotherapy alters tumor immunogenicity and its interaction with the host, inducing the death of immunogenic antigenic tumor cells and promoting dendritic cells (DC) and T cells to cross-present tumor-derived antigens [75]. At present, the checkpoint inhibitor anti-cytotoxic T-lymphocyte-associated protein 4 (anti-CTLA-4) and anti-programmed death-1 (anti-PD-1) are representative of the tumor immunotherapy program and have been widely studied. In 2011 and 2013, they were applied in clinical treatment respectively and their combinations with radiotherapy bring hope to tumor patients. CTLA4 blockade predominantly restrains $\mathrm{T}$ regulatory cells (Tregs) to increase the proportion of $\mathrm{CD} 8^{+} \mathrm{T}$ cells (CD8/ Treg). Anti-PD-1/PD-L1 relieves $\mathrm{T}$ cell exhaustion to mitigate depression in the CD8/Treg ratio and expand the distribution of oligo-clonal $\mathrm{T}$ cells. Irradiation facilitates the agonist diversity of the Toll-like receptors (TLRs) and maintenance or amplification of cancer cell immunogenicity.

\section{Ray-enhanced anti-CTLA-4 immunotherapy}

CTLA-4 is a leukocyte differentiation antigen located on the $\mathrm{T}$ cell membrane and functions as a transmembrane receptor. When it binds to a co-stimulatory molecule (B7) that is situated at the surface of APC, it induces T cells to be nonresponsive to cancer cells. CTLA-4 can down-regulate or terminate $\mathrm{T}$ cell- mediated immune responses by inhibiting $\mathrm{T}$ cell activity, which is consistent with the notion that CTLA-4 is a negative regulator of the anti-tumor immune response, demonstrating that antibody blockade of CTLA-4 could result in antitumor immunity in preclinical models. Although CTLA-4 antibodies bear good prospects, they are still limited to intrinsically immunogenic tumors. However, radiation therapy combined with anti-CTLA-4 monoclonal antibody treatment has made great progress in anti-tumor practice. Using a mouse model of breast cancer, Demaria et al. [76] found that the combination of local RT and CTLA-4 blockade significantly inhibited the growth and metastasis of primary tumors and produced better response outcomes in patients with spontaneous metastasis and low-immunogenicity breast cancer compared to treatment alone, and the intrinsic mechanism may be that combination therapy induces more $\mathrm{CD}^{+} \mathrm{T}$ cells with enhanced activity, which is propitious to CTLA-4 antibody-mediated tumor immunotherapy treatment. Additionally, a similar conclusion was drawn in colon cancer therapy by Son et al. [77]. Obviously, stimulating the immune defense system of the organism and improving the body's immune function can improve the efficiency of treating cancer.

\section{Achievements of radiation combined with anti -PD-1/PD-L1 immunotherapy}

Similar to anti-CTLA-4 immunotherapy, anti-PD-1/ PD-L1 monoclonal antibodies also play a positive role in tumor therapy and achieve greater progress when combined with radiotherapy. Antibodies targeting the PD-1/ PD-L1 checkpoint reverse immunocyte inhibition by blocking recognition of PD-1 located on Tregs or NK cells and PD-L1 expressed on tumor cells, and then restore the immunologic surveillance and anti-tumor abilities. PD-1 is a well-defined immune suppressor. Nvolumab and Pembrolizumab are PD-1 monoclonal antibodies (mAbs) that have been approved for clinical use with a lot achievement in improving efficacy [78, 79]. Zeng et al. [80] found that compared to a single treatment-alone, combination therapy with radiation and the PD-1 antibody not only increased the survival of mice implanted with intracranial gliomas by increasing the ratio of Tregs but also induced immune memory responses. Analogously, according to Sharabi et al. [81], compared with the control group, radiotherapy combined with PD-1 immunotherapy increased the infiltration of intratumoral T cells in established B16 and 4 T1 tumors. Furthermore, programmed death-ligand 1 (PD-L1) is also a potential target for immunotherapy, and atezolizumab, durvalumab and avelumab are PD-L1 antibodies that are currently the furthest in clinical development [82-84]. As certified by Deng et al. [85], ionizing radiation plus anti-PD-L1 antibody can activate cytotoxic $\mathrm{T}$ cells, which can reduce tumor-infiltrating bone marrow-derived inhibitory cells (MDSCs) through the cytotoxic actions of TNF, ultimately releasing $\mathrm{T}$ cell inhibition. Based on the above evidence, radiation can significantly enhance the effects of immunotherapy. Radiation combined with PD-1/PD-L1 monoclonal antibodies may have great promise and therapeutic potential for a variety of malignancies.

Although these monoclonal antibodies are currently the most promising immunotherapeutic anti-tumor drugs, their high cost of production and side effects, such as pneumonia, diarrhea and skin diseases, have limited their development which leaves way for PD-1/ PD-L1-targeting small molecule inhibitors to a broader field [86-88]. The pharmacokinetic behavior of small molecule inhibitors is highly controlled and well complementing the clinical shortcomings of macromolecular mAbs. CA-170, a class of small molecule inhibitors of 
PD-1/PD-L1 that can be orally administered, is already approved by the Food and Drug Administration (FDA) in the United States and is undergoing phase I clinical validation [89]. However, the number of PD-1/PD-L1 micro molecule inhibitors reported to date is very low due to the finite information on the interaction between PD-1 and PD-L1, and the impact of radiation on its therapeutic effect still remains elusive.

\section{TLR-mediated immunologic effects of RT}

TLRs are a class of important protein molecules that are involved in innate immunity, which can recognize damage-associated molecular patterns (DAMP), such as "danger" signal molecules released in the milieu upon RT. Tumor radiation results in upregulation or generation of tumor-associated antigens (TAA) and DAMPs including HMGB1 and HSPs [90, 91], which served as agonists of TLRs and thus primed "immunogenic cell death" via TLR-mediated signaling pathways. Under irradiation, systemic treatment of R848, a TLR7 agonist, leads to a dramatic boost of the anti-tumor efficiency in T cell lymphoma mouse models [92]. Alternatively, both Milas [93] and Mason [94] demonstrated that CpG enhances the immunologic effects of RT by activating TLR9 in fibrosarcoma mouse tumor models. Clinically, the combination of RT together with TLR modulators has been a major breakthrough for patients bearing esophageal squamous cell carcinoma or breast cancer [95, 96]. Irradiation, therefore, is a potential treatment for performing in-situ immunization because it can initiate the release of TAAs and stimulate APCs via endogenous release of DAMPs or TCR agonists.

Moreover, radiation maintains tumor specific molecular immunity and enhances the secretion of tumor cytokines (CXCL9, CXCL10 and CXCL16) to promote tumor immune recognition and $\mathrm{T}$ cell infiltration and inducing immunogenic cell death (ICD) [97]. RT is also able to promote chemokine-mediated effector T cells recruitment around tumor cells and trigger a distant effect (or bystander effect), which passes the radiation signal factor through the circulatory system to distant tumor cells or tissues [5, 98]. In summary, radiation influences the progression of cancer extensively, and its anti-tumor effects are dominant.

\section{Radiation-related tumor-promoting response}

Although radiation largely produces toxic effects on tumors from many aspects, we cannot deny the side effects of radiation, which can promote the occurrence and development of cancer. Experiments have shown that radiation induced the expression of TGF- $\beta$ in liver non-parenchymal cells (NPCs), which is able to promote the invasion and metastasis abilities of hepatocellular carcinoma cells (HCC) [99]. High doses of radiation are known to prime increased TGF- $\beta 1$ secretion by irradiated stroma, which is considered to be a larvaceous stimulatory agent in the late phases of carcinogenesis and metastasis dissemination [100]. Parker et al. [73] unearthed that the non-specific damage caused by radiation to normal cells increased the patient's lymphocyte damage and functional inhibition, which allowed immunogenicity-compromised tumor cells to escape immune surveillance. Worse still, radiation also activates immunosuppressive factors stimulating inhibitory immune cells such as Tregs and M2 macrophages that inhibit T and NK cell-mediated immune responses, thus, enhancing tumor aggressiveness [101-103]. Besides, changes in the tumor microenvironment in turn affect radiation-induced tumor repression. Hypoxia-triggered accumulation of adenosine, an essential tumor-microenvironmental factor (TMF), not only promotes tumor proliferation and angiogenesis directly but thwarts the RT-elicited antitumor immune responses [97]. Summarized by Vaupel et al. [104], apart from ADO, other TMFs, such as lactate accumulation, extracellular acidosis, VEGF overexpression and phosphatidylserine externalization driven by hypoxia, may also sabotage innate or therapeutically triggered antitumor immune responses. Therefore, the adoption of precise radiotherapy regimens in combination with immune checkpoint blockers $[81,105]$ and antibodies or molecule inhibitors targeting TMF is a promising attempt that will regulate systemic immunity response and ultimately achieve optimized therapeutic effect.

\section{Conclusion}

This review focuses on the relationship between radiation and tumor biology to clarify how radiation affects the biological structure and behavior of neoplasm cells, which is helpful for clinicians to achieve effective radiotherapy for maximal eradication of cancer cells while minimally killing normal ones. Although radiotherapy is a double-edged sword, with the development of molecular biology and radiation oncology, radiotherapy plays an increasingly important role in the treatment of cancer and lays a solid foundation for its clinical application. Radiation can damage DNA, organelles, and cell membrane or change the immunogenicity and microenvironment of tumor cells to regulate tumor cell apoptosis, proliferation, differentiation, migration and biological functions; additionally, it can activate a variety of signaling pathways to inhibit the body's immune response and promote tumor development. Thus, the dual effect of radiation and immunotherapy on the tumor will be a major topic in the future treatment of cancer. To obtain high-precision as well as low-damage radiotherapy efficacy, combining precise radiotherapy and chemotherapy or immunotherapy and other treatment methods is particularly attractive. 


\section{Abbreviations}

Anti-CTLA-4: Anti- cytotoxic T-lymphocyte-associated protein 4; Anti-PD1: Anti-programmed death-1; APC: Antigen presenting cells; ATM: Ataxia telangiectasia mutated; CCNA1: Cyclin A1; CRC: Colorectal cancer; Cytc: Cytochrome C; DAMP: Damage-associated molecular patterns; DC: Dendritic cells; DNA-PKcs: DNA-dependent protein kinase catalytic subunit; DSB: Double-strand breaks; EGFR: Epidermal growth factor receptor; EMT: Epithelial-mesenchymal transition; ERS: Endoplasmic reticulum stress; FDA: Food and Drug Administration; HCC: Hepatocellular carcinoma cells; HDR: High dose rate; HGF: Hepatocyte growth factor; HIF: Hypoxia inducible factor; iBCSCs: Induced breast cancer stem cells; ICD: Immunogenic cell death; iCSCs: Induced cancer stem cells; IFN-1: Interferon-1; JMJD2B: Jumonji domain-containing protein 2B; mAbs: Monoclonal antibodies; MDSCs: Marrow-derived inhibitory cells; MMPs: Matrix metalloproteinases; mtDNA: Mitochondrial DNA; NHEJ: Non-homologous end joining; NPCs: Nonparenchymal cells; Ptpn14: Protein tyrosine phosphatase non-receptor Type 14; RNS: Reactive nitrogen species; ROS: Reactive oxygen species; SREBP: Sterol regulatory element binding protein; SSB: Single-strand broken; TAA: Tumor-associated antigens; Tregs: T regulatory cells; UPRs: Unfolded protein response; VEGF: Vascular endothelial growth factor; VEGF-C: Vascular endothelial growth factor-C

\section{Acknowledgements}

The authors are appreciated for the valuable comments and discussions with each member of QHL and WHJ's group.

\section{Funding}

This work was financially supported by grants from the CAMS Innovation Fund for Medical Sciences (CIFMS) (No.2016-I2M-1-001); the National Basic Research Program of China (973 Program) (No. 2015CB553904); the National Natural Science Foundation of China (No. 81372158, 81372159, 81572842, 81672459); and the Independent Issue of State Key Laboratory of Molecular Oncology (No. SKL-2017-16).

\section{Authors' contributions}

WJS conducted the literature review and drafted the manuscript. WHJ contributed to review and edited and formatted the final manuscript. QHL edited and contributed to the revised manuscript. All authors have read and approved the final manuscript.

\section{Ethics approval and consent to participate}

Not applicable.

\section{Consent for publication}

Not applicable.

\section{Competing interests}

The authors declare that they have no competing interests.

Received: 28 November 2017 Accepted: 13 June 2018

\section{Published online: 30 June 2018}

\section{References}

1. Denis V, Couturier AM, Tedim FM, Amélie R, Poirier GG, Fabrice F, et al. DNA damage signalling and repair inhibitors: the long-sought-after Achilles' heel of cancer. Biomol Ther. 2015;5(4):3204-59.

2. Lewanski CR, Gullick WJ. Radiotherapy and cellular signalling. Lancet Oncol. 2001;2(6):366-70

3. Edimecheva IP, Kisel MA, Shadyro OI, Vlasov AP, Yurkova IL. The damage to phospholipids caused by free radical attack on glycerol and sphingosine backbone. Int J Radiat Biol. 1997;71(5):555-60.

4. Shao C, Folkard M, Michael BD, Prise KM. Targeted cytoplasmic irradiation induces bystander responses. Proc Natl Acad Sci U S A. 2004;101(37):13495-500.

5. Pilones KA, Vanpouille-Box C, Demaria S. Combination of radiotherapy and immune checkpoint inhibitors. Semin Radiat Oncol. 2015;25(1):28-33.

6. Van der Schans GP. Gamma-ray induced double-strand breaks in DNA resulting from randomly-inflicted single-strand breaks: temporal local denaturation, a new radiation phenomenon? Int J Radiat Biol Relat Stud Phys Chem Med. 1978;33(2):105-20

7. Saha S, Woodbine L, Haines J, Coster M, Ricket N, Barazzuol L, et al. Increased apoptosis and DNA double-strand breaks in the embryonic mouse brain in response to very low-dose $\mathrm{X}$-rays but not $50 \mathrm{~Hz}$ magnetic fields. J R Soc Interface. 2014;11(100):20140783.

8. Thopan P, Yu L, Brown IG, Tippawan U. Low-energy ion-species-dependent induction of DNA double-strand breaks: ion energy and fluence thresholds. Radiat Res. 2017;188(4):426-32.

9. Dauer LT, Brooks AL, Hoel DG, Morgan WF, Stram D, Tran P. Review and evaluation of updated research on the health effects associated with lowdose ionising radiation. Radia Pro Dosimetry. 2010;140(2):103-36.

10. Sak A, Stuschke M. Use of $\mathrm{yH} 2 \mathrm{AX}$ and other biomarkers of double-strand breaks during radiotherapy. Semin Radiat Oncol. 2010;20(4):223-31.

11. Collis SJ, Schwaninger JM, Ntambi AJ, Keller TW, Nelson WG, Dillehay LE, et al. Evasion of early cellular response mechanisms following low level radiation-induced DNA damage. J Biol Chem. 2004;279(48):49624-32.

12. Lowndes NF. DNA-damage signaling and apoptosis. Genome Biol. 2001; 2(11):REPORTS4028.

13. Lieber MR. The mechanism of double-strand DNA break repair by the nonhomologous DNA end-joining pathway. Annu Rev Biochem. 2010; 79:181-211.

14. Kakarougkas A, Jeggo PA. DNA DSB repair pathway choice: an orchestrated handover mechanism. Br J Radiol. 2014;87(1035):20130685.

15. Villanueva MT. DNA repair a new tool to target DNA repair. Nat Rev Cancer. 2015;15(3):136

16. Mello SS, Valente LJ, Raj N, Seoane JA, Flowers BM, McClendon J, et al. A p53 super-tumor suppressor reveals a tumor suppressive p53-Ptpn14-yap axis in pancreatic cancer. Cancer Cell. 2017:32(4):460-73.

17. Schwarz-Finsterle J, Scherthan H, Huna A, González P, Mueller P, Schmitt E, et al. Volume increase and spatial shifts of chromosome territories in nuclei of radiation-induced polyploidizing tumour cells. Mutat Res. 2013;756(1):56-65.

18. Pang $X L$, He G, Liu YB, Wang Y, Zhang B. Endoplasmic reticulum stress sensitizes human esophageal cancer cell to radiation. World J Gastroenterol. 2013;19(11):1736-48

19. Scheper W, Nijholt DA, Hoozemans JJ. The unfolded protein response and proteostasis in Alzheimer disease. Autophagy. 2011;7(8):910-1.

20. Meir O, Dvash E, Werman A, Rubinstein M. C/EBP-beta regulates endoplasmic reticulum stress-triggered cell death in mouse and human models. PLoS One. 2010;5(3):e9516.

21. Takada H, Kurisaki A. Emerging roles of nucleolar and ribosomal proteins in cancer, development, and aging. Cell Mol Life Sci. 2015;72(21):4015-25.

22. Zhang C, Yin C, Wang L, Zhang S, Qian Y, Ma J, et al. HSPC111 governs breast cancer growth by regulating ribosomal biogenesis. Mol Cancer Res. 2014;12(4):583-94.

23. Zhai C, Li Y, Mascarenhas C, Lin Q, Li K, Vyrides I, et al. The function of ORAOV1/ LTO1, a gene that is overexpressed frequently in cancer: essential roles in the function and biogenesis of the ribosome. Oncogene. 2014;33(4):484-94.

24. Youn H, Son B, Kim W, Jun SY, Lee JS, Lee JM, et al. Dissociation of MIF-rpS3 complex and sequential NF-KB activation is involved in IR-induced metastatic conversion of NSCLC. J Cell Biochem. 2015:116(11):2504-16.

25. Yang HJ, Youn $\mathrm{H}$, Seong KM, Jin YW, Kim J, Youn B. Phosphorylation of ribosomal protein S3 and antiapoptotic TRAF2 protein mediates radioresistance in nonsmall cell lung cancer cells. J Biol Chem. 2013;288(5):2965-75.

26. Ingrosso G, Fantini M, Nardi A, Benvenuto M, Sacchetti P, Masuelli L, et al. Local radiotherapy increases the level of autoantibodies to ribosomal P0 protein but not to heat shock proteins, extracellular matrix molecules and EGFR/ErbB2 receptors in prostate cancer patients. Oncol Rep. 2013;29(3):1167-74.

27. Kam WW, Banati RB. Effects of ionizing radiation on mitochondria. Free Radic Biol Med. 2013;65:607-19.

28. Walsh DWM, Siebenwirth C, Greubel C, llicic K, Reindl J, Girst S, et al. Live cell imaging of mitochondria following targeted irradiation in situ reveals rapid and highly localized loss of membrane potential. Sci Rep. 2017;7:46684.

29. Fachal L, Mosquera-Miguel A, Gómez-Caamaño A, Sánchez-García M, Calvo $P$, Lobato-Busto $R$, et al. Evaluating the role of mitochondrial DNA variation to the genetic predisposition to radiation-induced toxicity. Radiother Oncol. 2014;111(2):199-205.

30. Hamada N, Maeda M, Otsuka K, Tomita M. Signaling pathways underpinning the manifestations of ionizing radiation-induced bystander effects. Curr Mol Pharmacol. 2011;4(2):79-95.

31. Persson HL, Kurz T, Eaton JW, Brunk UT. Radiation-induced cell death: importance of lysosomal destabilization. Biochem J. 2005;389(3):877-84.

32. Kim TR, Lee HM, Lee SY, Kim EJ, Kim KC, Paik SG, et al. SM22alpha-induced activation of p16INK4a/retinoblastoma pathway promotes cellular 
senescence caused by a subclinical dose of $y$-radiation and doxorubicin in HepG2 cells. Biochem Biophys Res Commun. 2010;400(1):100-5.

33. Cheng AC, Hogan JL, Caffrey M. X-rays destroy the lamellar structure of model membranes. J Mol Biol. 1993;229(2):291-4.

34. Grzelińska E, Bartosz G, Gwoździński K, Leyko W. A spin-label study of the effect of gamma radiation on erythrocyte membrane. Influence of lipid peroxidation on membrane structure. Int J Radiat Biol Relat Stud Phys Chem Med. 1979;36(4):325-34.

35. Bartke N, Hannun YA. Bioactive sphingolipids: metabolism and function. J Lipid Res. 2009;50(Suppl):S91-6.

36. Vega VL, Rodríguez-Silva M, Frey T, Gehrmann M, Diaz JC, Steinem C, et al. Hsp70 translocates into the plasma membrane after stress and is released into the extracellular environment in a membraneassociated form that activates macrophages. J Immunol. 2008;180(6): 4299-307.

37. Srivastava PK, Menoret A, Basu S, Binder RJ, Mcquade KL. Heat shock proteins come of age: primitive functions acquire new roles in an adaptive world. Immunity. 1998;8(6):657-65.

38. Bayer C, Liebhardt ME, Schmid TE, Trajkovic-Arsic M, Hube K, Specht HM, et al. Validation of heat shock protein 70 as a tumor-specific biomarker for monitoring the outcome of radiation therapy in tumor mouse models. Int J Radiat Oncol Biol Phys. 2014;88(3):694-700.

39. Multhoff G, Pockley AG, Schmid TE, Schilling D. The role of heat shock protein $70(\mathrm{Hsp} 70)$ in radiation-induced immunomodulation. Cancer Lett. 2015;368(2):179-84.

40. Gastpar R, Gehrmann M, Bausero MA, Asea A, Gross C, Schroeder JA, et al. Heat shock protein 70 surface-positive tumor exosomes stimulate migratory and cytolytic activity of natural killer cells. Cancer Res. 2005;65(12):5238-47.

41. Wang YS, Liu SJ, Huang SC, Chang CC, Huang YC, Fong WL, et al. Recombinant heat shock protein 70 in combination with radiotherapy as a source of tumor antigens to improve dendritic cell immunotherapy. Front Oncol. 2012;2:149.

42. Goldkorn T, Balaban N, Shannon M, Matsukuma K. EGF receptor phosphorylation is affected by ionizing radiation. Biochim Biophys Acta. 1997;1358(3):289-99.

43. Lammering G, Valerie K, Lin PS, Hewit TH, Schmidt-Ullrich RK. Radiationinduced activation of a common variant of EGFR confers enhanced radioresistance. Radiother Oncol. 2004;72(3):267-73.

44. Park CM, Park MJ, Kwak HJ, Lee HC, Kim MS, Lee SH, et al. lonizing radiation enhances matrix metalloproteinase-2 secretion and invasion of glioma cells through Src/epidermal growth factor receptor-mediated p38/Akt and phosphatidylinositol 3-kinase/Akt signaling pathways. Cancer Res. 2006;66(17):8511-9.

45. Xu W, Luo T, Li P, Zhou C, Cui D, Pang B, et al. RGD-conjugated gold nanorods induce radiosensitization in melanoma cancer cells by downregulating $a(v) \beta_{3}$ expression. Int J Nanomedicine. 2012;7:915-24

46. Schweigerer $L$, Rave-Frank M, Schmidberger $H$, Hecht M. Subletha irradiation promotes invasiveness of neuroblastoma cells. Biochem Biophys Res Commun. 2005:330(3):982-8.

47. Hanahan D, Weinberg RA. Hallmarks of cancer: the next generation. Cell. 2011;144(5):646-74

48. Li W, Zhao L, Zang W, Liu Z, Chen L, Liu T, et al. Histone demethylase JMJD2B is required for tumor cell proliferation and survival and is overexpressed in gastric cancer. Biochem Biophys Res Commun. 2011 416(3-4):372-8.

49. Kim JG, Yi JM, Park SJ, Kim JS, Son TG, Yang K, et al. Histone demethylase JMJD2B-mediated cell proliferation regulated by hypoxia and radiation in gastric cancer cell. Biochim Biophys Acta. 2012;1819(11-12):1200-7.

50. Geraldo JM, Scalzo S, Reis DS, Leão TL, Guatimosim S, Ladeira LO, et al. HDR brachytherapy decreases proliferation rate and cellular progression of a radioresistant human squamous cell carcinoma in vitro. Int J Radiat Biol. 2017;93(9):958-66.

51. Lagadec C, Vlashi E, Donna LD, Dekmezian C, Pajonk F. Radiation-induced reprogramming of breast cancer cells. Stem Cells. 2012;30(5):833-44.

52. Jung JW, Hwang SY, Hwang JS, Oh ES, Park S, Han IO. lonising radiation induces changes associated with epithelial-mesenchymal transdifferentiation and increased cell motility of A549 lung epithelial cells. Eur J Cancer. 2007:43(7):1214-24.

53. Kumar A, Collins H, Van Tam J, Scholefield JH, Watson SA. Effect of preoperative radiotherapy on matrilysin gene expression in rectal cancer. Eur J Cancer. 2002;38(4):505-10.
54. Kumar A, Collins HM, Scholefield JH, Watson SA. Increased type-IV collagenase (MMP-2 and MMP-9) activity following preoperative radiotherapy in rectal cancer. Br J Cancer. 2000;82(4):960-5.

55. Speake WJ, Dean RA, Kumar A, Morris TM, Scholefield JH, Watson SA. Radiation induced MMP expression from rectal cancer is short lived but contributes to in vitro invasion. Eur J Surg Oncol. 2005;31(8):869-74.

56. Thiery JP, Sleeman JP. Complex networks orchestrate epithelialmesenchymal transitions. Nat Rev Mol Cell Biol. 2006:7(2):131-42.

57. Thiery JP. Epithelial-mesenchymal transitions in tumour progression. Nat Rev Cancer. 2002;2(6):442-54

58. Lee JM, Dedhar S, Kalluri R, Thompson EW. The epithelial-mesenchymal transition: new insights in signaling, development, and disease. J Cell Biol. 2006:172(7):973-81.

59. Kawamoto A, Yokoe T, Tanaka K, Saigusa S, Toiyama Y, Yasuda H, et al. Radiation induces epithelial-mesenchymal transition in colorectal cancer cells. Oncol Rep. 2012;27(1):51-7.

60. Zhang X, Li X, Zhang N, Yang Q, Moran MS. Low doses ionizing radiation enhances the invasiveness of breast cancer cells by inducing epithelialmesenchymal transition. Biochem Biophys Res Commun. 2011;412(1):188-92.

61. Chen YH, Pan SL, Wang JC, Kuo SH, Cheng JC, Teng CM. Radiation-induced VEGF-C expression and endothelial cell proliferation in lung cancer. Strahlenther Onkol. 2014;190(12):1154-62.

62. Bald T, Quast T, Landsberg J, Rogava M, Glodde N, Lopez-Ramos D, et al. Ultraviolet-radiation-induced inflammation promotes angiotropism and metastasis in melanoma. Nature. 2014;507(7490):109-13.

63. Chen Y, Xiaohong LI, Guo L, Xiaoyuan WU, Chunyu HE, Zhang S, et al. Combining radiation with autophagy inhibition enhances suppression of tumor growth and angiogenesis in esophageal cancer. Mol Med Rep. 2015; 12(2): 1645.

64. Liu Y, Zhang L, Liu Y, Sun C, Zhang H, Miao G, et al. DNA-PKcs deficiency inhibits glioblastoma cell-derived angiogenesis after ionizing radiation. J Cell Physiol. 2015;230(5):1094-103.

65. Maggio FM, Minafra L, Forte Gl, Cammarata FP, Lio D, Messa C, et al. Portrait of inflammatory response to ionizing radiation treatment. J Inflamm. 2015;12(1):14.

66. Miller GM, Andres ML. Gridley DS. NK cell depletion results in accelerated tumor growth and attenuates the antitumor effect of total body irradiation. Int J Oncol. 2003;23(6):1585-92.

67. Ye J, Livergood RS, Peng G. The role and regulation of human Th17 cells in tumor immunity. Am J Pathol. 2013;182(1):10-20.

68. Wang Q, Franks HA, Lax SJ, El Refaee M, Malecka A, Shah S, et al. The ataxia telangiectasia mutated kinase pathway regulates IL-23 expression by human dendritic cells. J Immunol. 2013;190(7):3246-55.

69. Katz LH, Li Y, Chen JS, Muñoz NM, Majumdar A, Chen J, et al. Targeting TGF- $\beta$ signaling in cancer. Expert Opin Ther Targets. 2013;17(7):743-60.

70. Greten TF, Manns MP, Korangy F. Immunotherapy of hepatocellular carcinoma. J Hepatol. 2006;45(6):868-78.

71. Demaria S, Formenti SC. Radiation as an immunological adjuvant: current evidence on dose and fractionation. Front Oncol. 2012;2(1-2):153.

72. Scheithauer H, Belka C, Lauber K, Gaipl US. Immunological aspects of radiotherapy. Radiat Oncol. 2014;9(1):185.

73. Parker JJ, Jones JC, Strober S, Knox SJ. Characterization of direct radiationinduced immune function and molecular signaling changes in an antigen presenting cell line. Clin Immunol. 2013;148(1):44-55.

74. Magné N, Toillon RA, Bottero V, Didelot C, Houtte PV, Gérard JP, et al. NFkappaB modulation and ionizing radiation: mechanisms and future directions for cancer treatment. Cancer Lett. 2006;231(2):158-68.

75. Keisari Y, Hochman I, Confino H, Korenstein R, Kelson I. Activation of local and systemic anti-tumor immune responses by ablation of solid tumors with intratumoral electrochemical or alpha radiation treatments. Cancer Immunol Immunother. 2014;63(1):1-9.

76. Demaria S, Kawashima N, Yang AM, Devitt ML, Babb JS, Allison JP, et al. Immune-mediated inhibition of metastases after treatment with local radiation and CTLA-4 blockade in a mouse model of breast cancer. Clin Cancer Res. 2005:11(1):728-34.

77. Son CH, Bae JH, Shin DY, Lee HR, Choi YJ, Jo WS, et al. CTLA-4 blockade enhances antitumor immunity of intratumoral injection of immature dendritic cells into irradiated tumor in a mouse colon cancer model. J Immunother. 2014:37(1):1-7.

78. Fessas P, Lee H, Ikemizu S, Janowitz T. A molecular and preclinical comparison of the PD-1-targeted T-cell checkpoint inhibitors nivolumab and pembrolizumab. Semin Oncol. 2017;44(2):136-40. 
79. Ivashko IN, Kolesar JM. Pembrolizumab and nivolumab: PD-1 inhibitors for advanced melanoma. Am J Health Syst Pharm. 2016;73(4):193-201.

80. Zeng J, See AP, Phallen J, Jackson CM, Belcaid Z, Ruzevick J, et al. Anti-PD-1 blockade and stereotactic radiation produce long-term survival in mice with intracranial gliomas. Int J Radiat Oncol Biol Phys. 2013;86(2):343-9.

81. Sharabi AB, Nirschl CJ, Kochel CM, Nirschl TR, Francica BJ, Velarde E, et al. Stereotactic radiation therapy augments antigen-specific PD-1-mediated antitumor immune responses via cross-presentation of tumor antigen. Cancer Immunol Res. 2015;3(4):345-55.

82. Santini FC, Rudin CM. Atezolizumab for the treatment of non-small cell lung cancer. Expert Rev Clin Pharmacol. 2017;10(9):935-45.

83. Powles T, O'Donnell PH, Massard C, Arkenau HT, Friedlander TW, Hoimes CJ, et al. Efficacy and safety of durvalumab in locally advanced or metastatic urothelial carcinoma: updated results from a phase 1/2 open-label study. JAMA Oncol. 2017;3(9):e172411.

84. Apolo AB, Infante JR, Balmanoukian A, Patel MR, Wang D, Kelly K, et al. Avelumab, an anti-programmed death-ligand 1 antibody, in patients with refractory metastatic urothelial carcinoma: results from a multicenter, phase lb study. J Clin Oncol. 2017;35(19):2117-24.

85. Deng L, Liang H, Burnette B, Beckett M, Darga T, Weichselbaum RR, et al. Irradiation and anti-PD-L1 treatment synergistically promote antitumor immunity in mice. J Clin Invest. 2014;124(2):687-95.

86. Michot JM, Bigenwald C, Champiat S, Collins M, Carbonnel F, Postel-Vinay S, et al. Immune-related adverse events with immune checkpoint blockade: a comprehensive review. Eur J Cancer. 2016;54:139-48.

87. Rizvi NA, Mazières J, Planchard D, Stinchcombe TE, Dy GK, Antonia SJ, et al. Activity and safety of nivolumab, an anti-PD-1 immune checkpoint inhibitor, for patients with advanced, refractory squamous non-small-cell lung cancer (CheckMate 063): a phase 2, single-arm trial. Lancet Oncol. 2015;16(3):257-65.

88. Kwak JJ, Tirumani SH, Van den Abbeele AD, Koo PJ, Jacene HA. Cancer immunotherapy: imaging assessment of novel treatment response patterns and immune-related adverse events. Radiographics. 2015;35(2):424-37.

89. Dawkins JB, Wang J, Maniati E, Heward JA, Koniali L, Kocher HM, et al. Reduced expression of histone methyltransferases KMT2C and KMT2D correlates with improved outcome in pancreatic ductal adenocarcinoma. Cancer Res. 2016;76(16):4861-71.

90. Asea A, Rehli M, Kabingu E, Boch JA, Bare O, Auron PE, et al. Novel signal transduction pathway utilized by extracellular HSP70: role of toll-like receptor (TLR) 2 and TLR4. J Biol Chem. 2002;277(17):15028-34.

91. Apetoh L, Ghiringhelli F, Tesniere A, Obeid M, Ortiz C, Criollo A, et al. Tolllike receptor 4-dependent contribution of the immune system to anticancer chemotherapy and radiotherapy. Nat Med. 2007;13(9):1050-9.

92. Dovedi SJ, Melis MH, Wilkinson RW, Adlard AL, Stratford IJ, Honeychurch J, et al. Systemic delivery of a TLR7 agonist in combination with radiation primes durable antitumor immune responses in mouse models of lymphoma. Blood. 2013;121(2):251-9.

93. Milas L, Mason KA, Ariga H, Hunter N, Neal R, Valdecanas D, et al. CpG oligodeoxynucleotide enhances tumor response to radiation. Cancer Res. 2004;64(15):5074-7.

94. Mason KA, Ariga H, Neal R, Valdecanas D, Hunter N, Krieg AM, et al. Targeting toll-like receptor 9 with $\mathrm{CpG}$ oligodeoxynucleotides enhances tumor response to fractionated radiotherapy. Clin Cancer Res. 2005;11(1):361-9.

95. Suzuki $Y$, Mimura K, Yoshimoto $Y$, Watanabe M, Ohkubo $Y$, Izawa S, et al. Immunogenic tumor cell death induced by chemoradiotherapy in patients with esophageal squamous cell carcinoma. Cancer Res. 2012;72(16):3967-76.

96. Ghiringhelli F, Apetoh L, Tesniere A, Andre F, Lidereau R, Delaloge S, et al. The TLR4 polymorphism predicts the response of breast cancer patients to anthracyclins. J Clin Oncol. 2007;25(Suppl 18):10612.

97. Vaupel P, Gabriele M. Adenosine can thwart antitumor immune responses elicited by radiotherapy. Strahlenther Onkol. 2016;192(5):279-87.

98. Mole $\mathrm{RH}$. Whole body irradiation; radiobiology or medicine? $\mathrm{Br} J$ Radiol. 1953;26(305):234-41.

99. Zhou LY, Wang ZM, Gao YB, Wang LY, Zeng ZC. Stimulation of hepatoma cell invasiveness and metastatic potential by proteins secreted from irradiated nonparenchymal cells. Int J Radiat Oncol Biol Phys. 2012;84(4):822-8.

100. Arshad A, Deutsch E, Vozenin MC. Simultaneous irradiation of fibroblasts and carcinoma cells repress the secretion of soluble factors able to stimulate carcinoma cell migration. PLoS One. 2015;10(1):e0115447.

101. Persa $E$, Balogh A, Sáfrány G, Lumniczky K. The effect of ionizing radiation on regulatory T cells in health and disease. Cancer Lett. 2015;368(2):252-61.
102. Demaria S, Golden EB, Formenti SC. Role of local radiation therapy in cancer immunotherapy. JAMA Oncol. 2015;1(9):1325-32.

103. Le QT, Shirato $H$, Giaccia AJ, Koong AC. Emerging treatment paradigms in radiation oncology. Clin Cancer Res. 2015;21(15):3393-401.

104. Vaupel P, Multhoff $G$. Accomplices of the hypoxic tumor microenvironment compromising antitumor immunity: adenosine, lactate, acidosis, vascular endothelial growth factor, potassium ions, and phosphatidylserine. Front Immunol. 2017;8:1887.

105. Schölch S, Rauber C, Tietz A, Rahbari NN, Bork U, Schmidt T, et al. Radiotherapy combined with TLR7/8 activation induces strong immune responses against gastrointestinal tumors. Oncotarget. 2015;6(7):4663-76.

\section{Ready to submit your research? Choose BMC and benefit from:}

- fast, convenient online submission

- thorough peer review by experienced researchers in your field

- rapid publication on acceptance

- support for research data, including large and complex data types

- gold Open Access which fosters wider collaboration and increased citations

- maximum visibility for your research: over $100 \mathrm{M}$ website views per year

At BMC, research is always in progress.

Learn more biomedcentral.com/submissions 